\title{
The Distribution and Valuation of Corporate Control
}

\author{
Elli Kraizberg ${ }^{* 1}$ and John L. Teall ${ }^{2}$ \\ ${ }^{I}$ Netanya Academic, School of Business Administration, 1 University St., Netanya 42365, Israel \\ ${ }^{2}$ Lally School of Management, Rensselaer Polytechnic Institute, Troy, NY 12180, USA
}

\begin{abstract}
Direct empirical valuation of corporate control has been hampered by the absence of systematic observable data and verifiable equilibrium models. This paper provides a new analytical framework for valuing voting rights, linking the value of control to the distribution of shares among shareholders along with corresponding Shapley and Owen Power Indices. The new framework presented here transforms values generated by power indices into game theory/equilibrium financial values We illustrate our model using numerical methodologies based on share prices paid by agents seeking to control firms as well as market prices paid by shareholders who simply defer control to other agents. The paper also derives a simple version of a demand function for corporate control in a setting similar to Jensen and Meckling [1]. Using a unique data set of dual class shares, we compare empirical methodologies estimating the value of control to the analytical methodology provided in this paper.
\end{abstract}

Keywords: Control value, vote value, dual share classes, power index, private benefits.

\section{INTRODUCTION}

This paper structures a new analytical power-based framework intended to value control of the firm as a function of the distribution of its shares, demand function for corporate control and equilibrium conditions that have not been applied in the literature. The model presented here is able to identify the value of control that is associated with shares that are traded in the market by non-control seekers. Using basic assumptions such as an initial "balance of threat" among various rivals who compete for control, the model generates a game theory/equilibrium solution so that values generated by power indices are transformed into equilibrium financial values. An important implication of the model is that overall corporate equity, net of the value of control, is not a simple product of prevailing share market prices and the number of outstanding shares, since even share prices that are held by non-control seekers include a control premium. Prevailing market prices of shares will reflect the distribution of control and the extent to which the transfer of particular shares might impact the outcome of a corporate election. Hence, the marginal value of control associated with a particular share being transferred is expected to be quite different from the average value of control reflected in the overall value of equity. Furthermore, the identities and characteristics of buyers and sellers of given shares impact the values of those shares without necessarily affecting the value of assets yielding private benefits.

This paper contributes to existing models valuing private benefits based on share class price differences (e.g., Lease, McConnell and Mikkelson [2] and [3] and Levy [4]) by incorporating the important relationship between shares distribution and value of corporate control. This paper has several

*Address correspondence to this author at the Netanya Academic, School of Business Administration, 1 University St., Netanya 42365, Israel;

E-mail: ekraizberg@yahoo.com additional contributions. It establishes equilibrium conditions that translate power indices into value, solving for voting right values using numerical methodologies. Although we apply restrictive assumptions to develop our model, we are able to extend our analytical framework later.

Corporate control has a definite value since its exercise may allot private benefits to individuals or inside shareholders at the expense of outside shareholders. Unless a particular shareholder or aligned group of shareholders owns an undisputed majority of votes associated with shares, uncertainty will exist regarding the extent of control that any single shareholder may exert. Nevertheless, the distribution of voting shares determines the shareholders' perceived or expected control level. Unfortunately, the value of this control and private benefits it may confer is somewhat problematic to infer. First, there do not exist well-developed markets for private benefits generated by firms and control-seekers have a strong incentive to obscure the value of control and its associated private benefits. Second, it is difficult to measure the ability to influence control and to infer this ability from share prices. Hence, the model in this paper values control and private benefits based on a combination of share prices and existing power models drawing on the distribution of shares.

Appropriate valuation of private benefits and corporate control has obvious important applications, including those directed toward share valuation, takeover strategy and government policy-making. Despite numerous recent scandals and negative media coverage, private benefits are by no means evils to be eliminated, rather they are assets that need to be understood, managed, valued and distributed appropriately. Private benefits can include managerial "psychic" income, managerial perquisites, opportunities arising from private information available to management and the ability to favor or divert resources towards other managerial interests. 
In this paper, we view the firm as a nexus of contracts among claimholders who serve their own self-interest as in Alchian and Demsetz [5], Jensen and Meckling [1] and Fama [6]. In particular, shareholders participate in the distribution of dividend flows and compete for control of the firm and private benefits. Dividend flows are distributed proportionally to share ownership or according to some pre-specified rule in the event of multiple classes of shares. Control and claims on private benefits are determined by the outcomes of voting contests. Shareholders compete to own shares along with their associated voting rights that are used to influence the distribution of private benefits.

One might value the equity-only firm as the sum of the values of dividend claims and private benefits, in line with the numerous variations of the Gordon [7] stock valuation model have been used to value dividends associated with shares. Two general frameworks for valuing private benefits currently exist in the literature. The first, employed by Nenova [8] and Dyck and Zingales [9] values private benefits as a function of the difference between the sum paid for each share as part of a controlling block and the price per share in the public market. The second framework employed by Lease, McConnell and Mikkelson [2] and [3] and DeAngelo and DeAngelo [10] in dual share class environments is based on the price difference between shares with differing voting rights. This paper offers a third framework drawing from share distributions among shareholders and power index models.

The value of the control component of a given equity share might be modeled as its contribution to the expected value of the private benefits to be realized by its ultimate owner. The key components of this expected value are the perceived probability that control will be exercised and the value of private benefits to be realized from this control. The Game Theory literature provides a number of useful techniques for estimating the probability associated with exercising control. The Power Index literature (e.g., Shapley and Shubik [11], Milnor and Shapley [12] and Owen [13]) has been applied to the valuation of corporate voting rights by Rydqvist [14], Bergstrom and Rydqvist [15], Robinson and White [16], Zingales [17] and Teall [18]. These game theoretic models and their applications can be used to infer power associated with votes and clusters of votes. While power index values bear strong relationships to vote values, direct valuation of votes from these models still requires valuation of private benefits. Zingales [19] and [17] has suggested that these power index models might be used to value private benefits once vote values are computed. Zwiebel [20] employs power indices to demonstrate how blockholders "create their own spaces," block other potential contestants for control and form coalitions even when they are clearly unable to obtain majority positions.

Several papers such as Levy [4] and Hauser and Lauterbach [21] have used price differences of superior voting class shares relative to inferior class shares to infer vote values. Although this empirical methodology is consistent with no-arbitrage conditions, it can only be used when liquid markets exist for two or more classes of shares. While there exists a large body of literature on private benefits and its determinants, technology to measure of its value remains untested. Our paper seeks to extend results of models em- ployed to value voting rights to the valuation of private benefits.

Our paper emphasizes the role of the outside shareholder (non-control seeker) in the valuation of votes and control, building on the observation of Zingales [19]:

\begin{abstract}
Votes allocate control. Therefore, even if outside shareholders do not enjoy these private benefits, they may attribute some value to voting rights as long as there is competition among different management teams to acquire those votes. In particular, votes held by small outside investors become very valuable when they are pivotal, that is when they are decisive in attributing control to any of the management teams fighting for it.
\end{abstract}

Zingales found that voting rights commanded a significant premium, generally between $10 \%$ and $20 \%$ of total stock value. Various studies found voting premiums on shares ranging from $5.4 \%$ in the U.S. (Lease, McConnell and Mikkelson [3]) to 82\% in Italy (Zingales [19]).

The financial, legal and accounting professions are voicing increasing concerns about the relative lack of appropriate models valuing corporate control. For example, a growing use of Family Limited Partnerships in the United States to discount estates for loss of control, redistributions of business interests due to divorce proceedings and a variety of other issues have heightened the need for improving our modeling of control value.

In a scenario more directly applicable to this paper, the Israeli legal system has been adjudicating a large number of cases involving share class reunifications. In the early 1980s, many firms whose shares were listed on the Tel Aviv Stock Exchange raised funds through the issue of inferior class shares, motivated by a desire to avoid dilution of control. The typical practice was to issue inferior class shares endowed with a dividend claim five times that of the dividend claim of superior shareholders. As required by law, both types of shares held one voting right per share. By the mid1990s, the Israeli SEC banned the issuance of inferior class shares (those with higher dividend claims or reduced voting rights). Consequently firms with dual class shares were able to raise funds solely through the issue of superior class shares. This move triggered a wave of "equalization of voting rights" class unifications. As of 2002, 106 firms had undergone this equalization process. This equalization process, which requires court approval, often awarded owners of superior class shares compensation for the loss of control through class unification. However, the judicial process issued awards in a very inconsistent manner and seemed to lack any sort of systematic procedure to value control.

We introduce our procedure to value control and its assumptions in Section 2 based on the existence of a single major shareholder who seeks control. Then, in Section 3, we extend our model to allow for two major contestants for control. Section 4 discusses a demand function for control, which acknowledges that managerial consumption of private benefits reduces managerial security benefits. Section 5 values corporate control and computational examples for our models are provided in Section 6. Conclusions are presented 
in Section 7 and computational procedures and power index models are detailed in the paper Appendix.

\section{INTRODUCTION TO THE MODEL: A SINGLE CONTROL-SEEKER}

The purpose of this stage of the model is to examine the distribution of control or power among shareholders. Since shareholders who are not interested in control issues may sell shares to shareholders seeking control, we pay close attention to the roles of non-control seekers. Under this perspective, the price of a given share of stock in the firm will be highly dependent on the extent to which a control seeker desires that particular share. Because shares may initially belong to particular shareholders who represent varying levels of threat to the control seeker's power, shares cannot be considered homogeneous. Hence, share prices will be a function of whether those shares are held by major shareholders and the extent to which the seller represents a threat to the shareholders who intend to exert control. We outline initial assumptions underlying our model as follows:

\begin{abstract}
Al - The incumbent managers along with the shareholders who support them hold a total of $N_{1}$ shares. This group of shareholders, collectively referred to as the incumbent management team, is assumed to derive some private nonsecurity benefits from their control of the firm.
\end{abstract}

A2 - We assume that a "balance of threat" or an initial equilibrium characterizes our initial framework; that is, initially, no control seeker has an incentive to vary their holdings.

A3 - We define each shareholder's claim on control benefits in terms of a normalized Power Index $P I_{i} \leq 1 .^{I}$ The Power Index is normalized such that when the single control seeker increases her holding to $N_{c}$ shares, the number required to attain an absolute majority, PI will converge to one. This power index is not necessarily a function of control value and it does not vary proportionately with investors' holdings of votes.

A4 - The sum across all $S$ shareholders of the benefits from controlling the firm is initially assumed to be a fixed amount, $V c$.

\section{A5 - The demand functions for control is public knowledge $e^{2}$.}

Assumption A4 will be revised later in our analysis. It is possible that control benefits may be divided and allocated among all market participants, including both control seekers and non-control seekers. Underlying assumption A4 is the condition that in equilibrium (referred to here as "balance of threat"), the overall value of control (the maximum value of private benefits available to any prospective controlling group) is dictated by the major shareholder as long as this

\footnotetext{
${ }^{1}$ A power index measures the power that a given shareholder has as a function of allocations of votes among all shareholders. The Shapley Power Index is described in Appendix 3.

${ }^{2}$ An interesting extension could apply the assumption of asymmetric information as in Christoffersen, Geczy and Musto and Reed [22].
}

major shareholder not change his holdings position. Later, when this assumption is relaxed by introducing a demand function for control, the model accounts for potential changes in the overall value of control. The change in the overall value of control is captured in two ways: first, the demand function for control of the major shareholder, which reflects his or her desire to obtain the control benefits, and, the Power Index. The Power Index also sets the attainable level of control, and sets various levels of control for various types of decisions (e.g., as per local security law). The Power Index sets these levels through the critical levels needed to obtain majority for certain decisions such as "simple majority rules," "absolute majority" or "special majority" rules. ${ }^{3,4}$

Consider an example where two control-seeking shareholders own the same number of shares and have equal control rights. Though their demand functions for control may be different, they block each other from obtaining higher levels of control and associated private benefits, thereby reducing significantly their own power indices.

We begin with a case in which a single control seeker holds $N_{1}$ shares. The remaining $S-1$ shareholders hold $N-N_{1}$ voting shares, where $N$ is the total number of voting shares. Given the initial assumption A4 that the overall value of control benefits is a fixed constant $V c$, the sum value of dividend claims share is $E$ as follows:

$E=(V-V c) / N$.

where $V$ is the overall value of the firm. Defining $V c_{j}$ as the expected value of control benefits realized by the shareholder $\mathrm{j}$ owning a total of $N$ shares, we define overall firm control value as:

$V c=\sum_{j=1}^{S} V c_{j}$

where $S$ is the total number of shareholders. Thus, equation (1), becomes:

$E=\left(V-\sum_{j=1}^{S} V c_{j}\right) / N$

We define each shareholder's claim on control benefits in terms of a normalized Power Index $P I_{i}$ where $0 \leq P I_{i} \leq 1 \forall i$ and $\sum_{i=1}^{S} P I_{i}=1$. The value of control is a function of the power index, $P I$; i.e., $\quad V c_{1}=V c f\left(P I_{N 1}\right)$ such that $0 \leq f\left(P I_{N i}\right) \leq 1$ and $f\left(P I_{N c}\right)=1$. If we define $f_{1}($.$) and f_{2}($. $)$ to be the value of control for two different players, then $f_{1}\left(P I_{N 1}\right)=f_{i}\left(P I_{N i}\right) \forall i$. The maximum price the control seeker is willing to pay for $\Delta N$ additional shares is a function of the incremental change in $f($.$) (note that based on (2)$

\footnotetext{
${ }^{3}$ Assuming monotonic increasing value of control even at the points where the legal status changes.

${ }^{4}$ The Security Law in Israel, for example, requires that only the nonmajority shareholders may vote decisions that are directly related to majority shareholders.
} 
$V c$ represents the overall value of control while $V c_{i}$ represents and individual's value) :

$$
V c\left(f\left(P I_{N 1+\Delta N}\right)-f\left(P I_{N 1}\right)\right) \forall \Delta N, \Delta N=1,\left(N_{c}-N_{1}\right)
$$

The shareholder will be willing to pay an average per share price equal to:

$$
V c\left(f\left(P I_{N 1+\Delta N}\right)-f\left(P I_{N 1}\right)\right) / \Delta N>0
$$

All other shareholders have full knowledge of the control seeker's position. Additionally, we make the assumption that other shareholders may be willing to purchase voting shares by paying for the value of control imbedded in the market price, anticipating position changes on the part of the control seeker.

There are $N-N_{1}$ shares in the market, out of which the control seeker contemplates buying $\Delta N$ shares through a tender offer or in the open market. Thus, the probability a shareholder holding only one share will have that share purchased by the control-seeker is $\Delta N /\left(N-N_{1}\right)$, and the expected value of a gain for a non-control seeker who owns this single share may be as high as: ${ }^{5}$

$$
\begin{aligned}
& V c \frac{\Delta N}{\left(N-N_{1}\right)} \frac{\left(f\left\{P I_{N 1+\Delta N}\right\}-f\left\{P I_{N 1}\right\}\right)}{\Delta N} \\
& =V c\left(f\left\{P I_{N 1+\Delta N}\right\}-f\left\{P I_{N 1}\right\}\right) /\left(N-N_{1}\right)
\end{aligned}
$$

Thus, any non-control seeker $j$, would be willing to buy a voting share and pay a market price $P_{m}$ for a single voting right:

$P_{m}=V c \cdot \rho \cdot f\left(P I_{N 1+\Delta N}-f\left\{P I_{N 1}\right\}\right) /\left(N-N_{1}\right)$

where $\rho$ executes the transformation of an expected value into its Certainty Equivalent, $0<\rho<1$. This transformation is assumed to be constant over all investors, and will be used in the simulation procedure.

Since the total value of control imbedded in shares sums to $V c$, the value of control associated with the holding of the control seeker

$$
\left.V c_{1}=V c \cdot \rho \cdot f\left\{P I_{N 1}\right]\right\} \text {, }
$$

plus the value of control associated with the sum of other voting shares:

$$
\begin{aligned}
\sum V c_{j} & \left.=V c \cdot\left(N-N_{1}\right) \cdot f\left\{\left(P I_{N 1+\Delta N}-P I_{N 1}\right)\right\} /\left(N-N_{1}\right)\right\} \\
& =V c \cdot f\left\{\left(P I_{N 1+\Delta N}-P I_{N 1}\right)\right.
\end{aligned}
$$

will sum to $V c$ under assumption $A 2$ since the power indices are normalized.

In a scenario with a single control seeker, we demonstrate that $V c_{j}$ may be driven to zero and $V c_{1}=1$. The control seeker who owns $N_{1}$ shares and contemplates purchas-

\footnotetext{
${ }^{5}$ It is possible that the market prices the probability based on clusters of shares. If a shareholder owns more than one share, and the above market pricing is based on a single share, he might not accept the price based on a single share.
}

ing $\Delta N$ additional shares, $\Delta N=1 \ldots N_{c}-N_{1}$, is willing to offer at most

$V c \cdot\left[f\left\{P I_{N 1+\Delta N}\right\}-f\left\{P I_{N 1}\right\}\right] / \Delta N$

per share in the case of a tender offer $(\rho=1)$, and:

$V c \cdot \sum_{N 1}^{N 1+\Delta N} \rho f\left[\left\{P I_{N 1+\Delta N}\right\}-f\left\{P I_{N 1}\right\}\right]$

for all the shares that she purchases one by one in the open market. However, the market price for the control premium is given by (7). In this scenario with symmetric information availability to all participants, the lone control seeker will purchase shares at non-control seeker reservation prices rather than her own maximum offer price.

Thus, the market price declines such that the single control seeker can purchase shares reducing the market price of voting rights to zero. Since all market shares carry no control premium $\left(V c_{j}=0\right)$, the entire value of control, $V c$, is allocated to the control seeker. Since the single control seeker possesses all the value of control, investors have no incentive to vary their holdings. The market for control retains its equilibrium, the market price $P_{m}$ of each vote is zero and the single control seeker retains all of the value of control:

$\left[V c\left[f\left\{P I_{N 1+\Delta N}\right\}-f\left\{P I_{N 1}\right\}\right]\right]=P \Delta N_{1}=0$

$V c\left[f\left(P I_{N 1}\right)\right]+\left(N-N_{1}\right) P_{m}=V c$

$P_{m}=\rho\left[\Delta N_{1} /\left(N-N_{1}\right)\right] P=0$

Since this scenario presents a single control owner with no potential or actual rivals, the lower bound on $P$ is zero. There is no reason for the control owner to offer more than $P_{m}=0$. However, the market price implied by (13) assumes the single control seeker maintains monopsony power. On the other hand, if a potential or actual rival control seeker is introduced into the framework, pricing and distribution of control is quite different.

\section{MULTIPLE CONTROL SEEKERS}

In this section, we introduce a rival control seeker. The largest shareholder group is taken to be the major shareholder as well as the incumbent management team. Both the management team and its rival for control know their opponent's shareholding positions and react to changes in these positions. Share prices respond accordingly.

There exists a single market price at which non-control seekers exchange voting shares, though this price changes as the distribution of shares changes. We maintain the same assumptions as in the previous section. Furthermore, we assume that incumbent management team owns $N_{1}$ shares and that the potential rival owns $N_{2}$ shares. Each of them possess some power as measured by a Power Index, PI, which leads to some unique value of control $f\{P I\}$. $f($.) is a continuous function and is identical (symmetric) for both rivals, $0 \leq f\{P I\} \leq 1$. 
Suppose that the rival contemplates seizing control by purchasing shares in the open market. Obviously, he would take this action only if its potential benefits (the additional value of control) exceed its costs (the market price of voting rights). Disregarding potential reactions of the incumbent management team, the rival would be willing to purchase an additional vote for a price not exceeding:

$P_{r}=V c\left[f\left(P I_{N_{2}+1}\right)-f\left(P I_{N_{2}}\right)\right]$, or,

$P_{r}=V c\left[\frac{\partial f\left(P I_{N_{2}}\right)}{\partial N_{2}}\right]$ if $f($.$) is continuous and N$ is approaching infinity.

The maximum price the rival is willing to pay for $\Delta N$ additional shares via a tender offer is:

$P_{r}=V c\left[f\left\{P I_{N 2+\Delta N 2}\right\}-f\left\{P I_{N 2}\right\}\right] / \Delta N_{2}$

The maximum average price when the shares are purchased one by one in the open market is:

$P_{r}=V c\left[\sum_{n=1}^{\Delta N_{2}} f\left\{P I_{N 2+b}\right\}-f\left\{P I_{N 2}\right\}\right] / \Delta N_{2}$, or,

$P_{r}=V c \int_{N_{2}}^{N_{2}+\Delta N_{2}}\left\{f\left(P I_{N_{2}}\right) d N_{2}\right\} / \Delta N_{2}$, as the number of

shares approaches infinity.

where vote purchases yield diminishing marginal benefits and the rival has fewer shares than the incumbent controlowner, we expect $P_{r}$ to be higher than the price offered by the incumbent. However, the incumbent's reactions to rival bidding strategy may change this. Where the incumbent control-owner reacts to the rival's purchase of $\Delta N_{2}$ shares, the incumbent control-owner will not only anticipate, but also react by purchasing $\Delta N_{1}$ shares to protect his initial level of control. Thus:

$$
f\left(P I_{N_{1}}\right)=f\left(P I_{N_{1}+d N_{1} \mid N_{2}+d N_{2}}\right)-d N_{1} P_{c} \quad \forall d N_{2}, d N_{2}=0 \ldots . N_{c}-N_{2}
$$

where $P_{c}$ is the offering price of the incumbent control owner while $P_{r}$ is that of the rival. $f\left(P I_{N(.) / N(.)}\right)$ represents a position $N($.) of one shareholder while the other holds $N(.$.$) .$ ply: ${ }^{6}$

$P_{c}=V c\left[\frac{f\left(P I_{N_{1}+d N_{1} \mid N_{2}+d N_{2}}\right)-f\left(P I_{N_{1}}\right)}{\Delta N_{1}}\right] \geq P_{r}=$

$V c\left[\frac{f\left(P I_{N_{2}+d N_{2} \mid N_{1}+d N_{1}}\right)-f\left(P I_{N_{2}}\right)}{\Delta N_{2}}\right]$

$P_{c}$ must be non-negative for any potential move since $f(P I) \leq 1$ and because of our "balance of threat" condition specified below. In other words, in an extreme case scenario, the incumbent may move to reach $N_{c}$ for which $f($.) is

\footnotetext{
${ }^{6}$ The "Balance of threat" condition here parallels shareholders "creating
} their own space" in Zwiebel [20]. greater than the initial position. But the incumbent manager who can benefit by offering (17) needs to offer only $P_{r}+\varepsilon$.

The market price, $P_{m}$, represents the trading price among non-control seekers who anticipate potential reactions by the control seekers. In this section, we obtain the minimum price $P_{r}$ that the incumbent manager may offer for a vote. Purchasing a block of shares through a tender offer may have pricing and control implications that are quite different from purchasing shares one at a time (See Burkart, Gromb and Panuzzi [23]). We summarize for the case of tender offer extended by the rival with the following equations representing the two conditions specified above and setting the market price:

(i) The "balance of threat" condition preventing challenges by other blockholders (See Zwiebel [20]):

$V c\left[f\left\{P I_{N 2+\Delta N 2 \mid N 1+\Delta N 1}\right\}-f\left\{P I_{N 2 \mid N 1}\right\}\right]=\Delta N_{2} P_{r}$

(ii) Setting the market price, where $\Delta \mathrm{N}_{2} /\left(\mathrm{N}-\mathrm{N}_{1}-\mathrm{N}_{2}\right)$ represents the probability that a share of a given non-control seeker's will be purchased by the rival:

$p_{m}=\rho \frac{\Delta N_{2}}{N-N_{1}-N_{2}} P_{r}$

(iii) Constant overall value of control (maximum value of private benefits available to a prospective control group):

$V c\left[f\left\{P I_{N 1 \mid N 2}\right\}+f\left\{P I_{N 2 \mid N 1}\right\}\right]+\left(N-N_{1}-N_{2}\right) p_{m}=V c$

Incorporating (19) into (20) yields:

$V c\left[f\left\{P I\left(\left(_{N_{1}, N_{2}}\right)\right\}+f\left\{P I\left(\left(_{N_{2}, N_{1}}\right)\right\}\right]+\left(\Delta N_{2}\right) p_{r}\left(N_{1}, N_{2}\right)=V c\right.\right.$ tion:

Incorporating (15A) into (20A) yields the valuation equa-

$\left[f\left(P I_{N 1 \mid N 2}\right)+(1-\rho) f\left(P I_{N 2 \mid N 1}\right)+\rho \cdot f\left(P I_{N 2+\Delta N 2 \mid N 1+\Delta N 1}\right)\right]=1$

We use this valuation equation (21) to obtain the market price of the vote to be bid on by the rival. Solving (21) and obtaining the vote value can be accomplished with the use of a Finite Difference Numerical Method (Forsythe and Wasow [24]), and the iteration procedure is demonstrated in Appendix A1. Table 1 provides results from a computational example using a Shapley Power Index.

\section{THE DEMAND FUNCTION FOR CONTROL}

In this section we relax the assumption that the overall value of control is fixed. Following Jensen and Meckling [1], we now assume that each control seeker's demand function for control benefits is decreasing in his level of security benefits. This decreasing relationship exists because private benefit consumption reduces security benefits associated with holding and increased shareholdings increases the manager's cost of private benefits consumption.

We define the demand function in its general form as $V c_{i}=g\left\{N_{i}\right\}$. Initially, we shall assume that this demand function is identical for all control seekers. Then, we will allow these demand functions to vary among shareholders. The manager's number of shares determines his level of de- 
Table 1. The Fractional Value of Control Owned by Player 1 (Vertical Column) when his Opponent (Player 2) Owned the Fraction of Shares Shown in the First Row $(\rho=.05)$.

\begin{tabular}{|c|c|c|c|c|c|c|}
\hline $\mathbf{0 . 5}$ & $\mathbf{0 . 4}$ & $\mathbf{0 . 3}$ & $\mathbf{0 . 2}$ & $\mathbf{0 . 1}$ & $\begin{array}{c}\text { Fraction of Shares } \\
\text { Player 1/Player 2 }\end{array}$ \\
\hline \hline 0 & 0 & 0 & 0 & 0 & 0 & 0 \\
\hline 0 & 0.081295 & 0.176984 & 0.253769 & 0.326309 & 0.504892 & 0.1 \\
\hline 0 & 0.119776 & 0.292941 & 0.412312 & 0.551731 & 0.709454 & 0.2 \\
\hline 0 & 0.192198 & 0.375604 & 0.553283 & 0.682162 & 0.814601 & 0.3 \\
\hline 0 & 0.326222 & 0.535174 & 0.661218 & 0.77096 & 0.877932 & 0.4 \\
\hline
\end{tabular}

mand. In the initial equilibrium, this level is independent of the rival's demand function for shares. While we assumed earlier that the control value is fixed, we now establish the following two conditions for share-based control demand functions:

\section{(i) The Balance of Threat or Equilibrium Condition}

The major shareholder is willing to pay no more than the following for a voting right:

$$
P c=\rho \frac{\left(g\left(\left(_{N 1+\Delta N 2}\right) f\left(P I_{N 1+\Delta N 2 \mid N 2+\Delta N 2}\right)-g\left({ }_{N 1}\right) f\left(P I_{N 1 \mid N 2}\right)\right)\right.}{\Delta N_{2}},
$$

while the rival may offer as much as:

$\operatorname{Pr}=\rho \frac{\left(g\left(_{N 2+\Delta N 2}\right) f\left(P I_{N 2+\Delta N 2 \mid / N 1+\Delta N 2}\right)-g\left({ }_{N 2}\right) f\left(P I_{N 2 \mid N 1}\right)\right)}{\Delta N_{1}}$

In contrast to the case of constant value control, is no longer necessarily true that the offering price of the incumbent shareholder is higher than that of his rival. In fact, the rival's price may be higher because of the demand function for control. Regardless of higher prices, no control seeker will offer more than his opponent's offer plus epsilon. Thus, the market sets a price $P s$, where $P s=\min \{P c, \operatorname{Pr}\}$. Given the same reasoning as in the previous section, the market price $P m$ of a single voting right would be:

$$
\begin{aligned}
& P m=\frac{\Delta N_{2}}{N-N_{1}-N_{2}} P S= \\
& \frac{\Delta N_{2}}{N-N_{1}-N_{2}} M I N\left\{\begin{array}{l}
\rho \frac{\left(g\left(_{N 1+\Delta N 2}\right) f\left(P I_{N 1+\Delta N 2 \mid N 2+\Delta N 2}\right)-g\left({ }_{N 1}\right) f\left(P I_{N 1 \mid N 2}\right)\right)}{\Delta N_{2}} \\
\rho \frac{\left(g\left(\left(_{N 2+\Delta N 2}\right) f\left(P I_{N 2+\Delta N 2 \mid N 1+\Delta N 2}\right)-g\left(N_{N 2}\right) f\left(P I_{N 2 \mid N 1}\right)\right)\right.}{\Delta N_{2}}
\end{array}\right\}
\end{aligned}
$$

\section{(ii) The Overall Value of Control}

Although the overall value of control that sets the market price of voting rights is not a constant, it can be expressed as a function of the contestants' holdings,

$$
\tilde{V} c=\left(\operatorname{MIN}\left\{\begin{array}{l}
\left(g\left(_{N 1+\Delta N 2}\right) f\left(P I_{N 1+\Delta N 2 \mid N 2+\Delta N 2}\right)-g\left(\left(_{N 1}\right) f\left(P I_{N 1 \mid N 2}\right)\right)\right. \\
\left(g\left(_{N 2+\Delta N 2}\right) f\left(P I_{N 2+\Delta N 2 \mid N 1+\Delta N 2}\right)-g\left(\left(_{N 2}\right) f\left(P I_{N 2 \mid N 1}\right)\right)\right.
\end{array}\right\}\right)
$$

If, for example, the incumbent manager obtains the minimum, $\tilde{V} c$ will be set by his demand function. Thus, the overall value of control is as follows:

$\left[g\left(_{N 1}\right) f\left(P I_{N 1 \mid N 2}\right)+g\left({ }_{N 2}\right) f\left(P I_{N 2 \mid N 1}\right)\right]+\left(N-N_{1}-N_{2}\right) P m=\tilde{V} c$

For sake of illustration, consider a particular case in which the demand function for control is linear in share ownership as in Jensen and Meckling [1]:

$g\left(N_{N_{i}}\right)=\bar{V} c-a N_{i}$

Let $\bar{V} c$ be the maximum demand for control obtained when the control seeker has no dividend claim and is only able to obtain private benefits, costing him nothing. The private benefits are provided at the expense of outside shareholders. When outside shareholders i own all shares, $N_{i}=N$ and $\bar{V} c=a N_{i}$, such that $g(N)=0$.

The market price of shares is based on the quantity of control demanded by the rival when he offers less for voting rights. The rival who offers more will be able to successfully bid for votes and exert control based on his incumbent's failure to pose a viable bid. Thus the incumbent or the leading rival's behavior primarily influences the overall value of control. Whoever offers the least determines the overall market value of shares owned by non-control seekers. The leading contestant's demand function for control determines:

$$
\begin{aligned}
& \left(\bar{V} c-a N_{1}\right) f\left(P I_{N 1, N 2}\right)+\left(\bar{V}_{c}-a N_{2}\right) f\left(P I_{N 2, N 1}\right)+ \\
& \operatorname{MIN}\left\{\begin{array}{l}
\rho\left(\left(\bar{V} c-a\left(N_{1}+\Delta N_{2}\right)\right) f\left(P I_{N 1+\Delta N 2, N 2+\Delta N 2}\right)-\left(\bar{V}_{c}-a N_{1}\right) f\left(P I_{N 1, N 2}\right)\right) \\
\rho\left(\left(\bar{V} c-a\left(N_{2}+\Delta N_{2}\right)\right) f\left(P I_{N 2+\Delta N 2, N 1+\Delta N 2}\right)-\left(\bar{V}_{c}-a N_{2}\right) f\left(P I_{N 2, N 1}\right)\right)
\end{array}\right\}=\breve{V}_{c}
\end{aligned}
$$

while:

$\breve{V} c=\left(\operatorname{MAX}\left\{\begin{array}{l}\left(\left(\bar{V}_{c}-a\left(N_{1}+\Delta N_{2}\right)\right) f\left(P I_{N 1+\Delta N 2, N 2+\Delta N 2}\right)-\left(\bar{V}_{c}-a N_{1}\right) f\left(P I_{N 1, N 2}\right)\right) \\ \left(\left(\bar{V} c-a\left(N_{2}+\Delta N_{2}\right)\right) f\left(P I_{N 2+\Delta N 2, N 1+\Delta N 2}\right)-\left(\bar{V} c-a N_{2}\right) f\left(P I_{N 2, N 1}\right)\right)\end{array}\right\}\right)$

Equation (28) can be expressed in terms of two mutually exclusive equations: 
Table 2. The Fractional Value of Control Owned by Player 1 (Vertical Column) when his Opponent (Player 2) Owned the Fraction of Shares Shown in the First Row $(\rho=.05)$.

\begin{tabular}{|c|c|c|c|c|c|c|}
\hline $\begin{array}{c}\text { Fraction of Shares } \\
\text { Player 1/Player 2 }\end{array}$ & $\mathbf{0}$ & $\mathbf{0 . 1}$ & $\mathbf{0 . 2}$ & $\mathbf{0 . 3}$ & $\mathbf{0 . 4}$ & $\mathbf{0 . 5}$ \\
\hline \hline 0 & 0 & 0 & 0 & 0 & 1 \\
\hline 0.1 & 0.511929 & 0.327664 & 0.252197 & 0.174068 & 0.087762 & 1 \\
\hline 0.2 & 0.72862 & 0.561003 & 0.415065 & 0.314703 & 0.129034 & 1 \\
\hline 0.3 & 0.847881 & 0.702912 & 0.56405 & 0.378701 & 0.191398 & 1 \\
\hline 0.4 & 0.926844 & 0.836739 & 0.723334 & 0.587402 & 0.357472 & 1 \\
\hline 0.5 & 0 & 0 & 0 & 0 & 0 \\
\hline
\end{tabular}

The Shapley Power index was used for 1000 shares. The demand function assumed here is with $\mathrm{b}=1.5$. Given empirical data, the slope of the demand function may be extrapolated.

$(1-\rho)\left(\bar{V} c-a N_{1}\right) f\left(P I_{N 1, N 2}\right)+\left(\bar{V} c-a N_{2}\right) f\left(P I_{N 2, N 1}\right)+$

$\left.\rho\left(\bar{V} c-a\left(N_{1}+\Delta N_{2}\right)\right) f\left(P I_{N 1+\Delta N 2, N 2+\Delta N 2}\right)\right)=\bar{V} c-a N_{2}$

or

$\left(\bar{V} c-a N_{1}\right) f\left(P I_{N 1, N 2}\right)+(1-\rho)\left(\bar{V} c-a N_{2}\right) f\left(P I_{N 2, N 1}\right)+$

$\left.\rho\left(\bar{V} c-a\left(N_{2}+\Delta N_{2}\right)\right) f\left(P I_{N 1+\Delta N 2, N 2+\Delta N 2}\right)\right)=\bar{V} c-a N_{1}$

From (25) it appears that either

$\left(\left(V c-a\left(N_{2}+\Delta N_{2}\right)\right) f\left(P I_{N 2+\Delta N 2, N 1+\Delta N 2}\right)-\left(\bar{V} c-a N_{2}\right) f\left(P I_{N 2, N 1}\right)\right)$

or

$\left(\left(V c-a\left(N_{1}+\Delta N_{2}\right)\right) f\left(P I_{N 2+\Delta N 2, N 1+\Delta N 2}\right)-\left(\bar{V} c-a N_{2}\right) f\left(P I_{N 2, N 1}\right)\right)$

which comprise the minimum of the contestants' offer prices. This system is solved in Appendix A.2.

The following are simulation results for a simple linear demand function (with a slope $\beta=1.5$ and $\rho=.05$ )

\section{VALUING CORPORATE CONTROL}

In this section, we first calculate a lower bound on the value of control, irrespective of the model or specific power index. This is accomplished by assuming that all inferior shares are held solely by the non-control seeking public shareholders $j$. After determining this lower bound on control, we will apply our model to calculate the actual value of control.

The model from the previous section requires application of a specific power index model. We utilize two alternative power indices, the Shapley Oceanic Index (Milnor and Shapley [12]) and a binomial variation of the Owen [13] model. Generally, when power index models appear in financial literature, such as Rydqvist [14], and Zingales [17]), only the Shapley Index is computed (Shapley and Shubik [11]). The Shapley Oceanic and Owen Indices more appropriately capture the roles of the infinitesimal non-controlling shareholders than other models.

\section{5.a. Dual Class Shares}

Suppose that a firm has $N_{s}$ superior class, and $N_{I}$ inferior class shares, and that all shares have one vote each. ${ }^{7}$ However, the claim on cash flows (dividends) of each inferior share is $n$ times that of each superior share.

\begin{tabular}{|l|l|l|}
\hline Type of Share & Claim for Dividends & Share in Voting Rights \\
\hline Superior & $\frac{N_{s}}{N_{s}+n N_{I}}$ & $\frac{N_{s}}{N_{s}+N_{I}}$ \\
\hline Inferior & $\frac{n N_{I}}{N_{s}+n N_{I}}$ & $\frac{N_{I}}{N_{s}+N_{I}}$ \\
\hline
\end{tabular}

The market prices of the superior and inferior shares are $P_{s}$ and $P_{I}$ such that $P_{I} / n \leq P_{s}^{8}$

In our framework, the value of control associated with each vote is a function of the shareholder and not the share itself. Thus, a control seeker who owns $N_{i s}$ superior shares and $N_{i I}$ inferior shares $0 \leq N_{i s}+N_{i I}<N$, is defined as someone who may legally ${ }^{9}$ obtain control. The remaining shareholders $j$ hold $N_{j s}, N_{j I}$ shares, numbers which are presumed to be relatively small. In a world of comprehensive knowledge of control seekers' holdings and their potential moves, the market price for voting rights is set so that an investor $\mathrm{j}$ would neither experience a sure or unpredictable loss as a result of a control seeker's behavior.

\footnotetext{
${ }^{7}$ See data description from the Tel Aviv Stock Exchange in Section 6.

${ }^{8}$ There is one case, based on Israeli securities Law, in which the value of the superior share could in principle be smaller than the inferior share when one holds $24.9 \%$ of the share. Once one's holding reaches $25 \%$, he or he may lose the protection of another Law that attempts to prevent minority exploitation (see "Levels of control"). Dyck and Zingales [9] discuss similar cases. ${ }^{9}$ Some financial institutions in Israel are banned from having control in publicly traded firms.
} 


\section{5.b. A Lower Bound On The Value Of Control with Dual-Class Shares}

Given market prices of superior and inferior shares, $P_{s}$ and $P_{I}$, we establish the following bounds on control value $V_{c}$ :

$V_{c} \geq \dot{V}_{c} \geq \ddot{V}_{c}$

where $V_{c}$ is the actual overall value of control, and $\dot{V}_{c}$ and $\ddot{V}_{c}$ are the lower bounds. $\dot{V}_{c}$ is the value of control when calculated based on the marginal value of voting rights imbedded in market prices and $\ddot{V}_{c}$ is control value when the market price of inferior shares does not reflect voting rights ${ }^{10}$. Thus:

$\dot{V}_{c}=\left(P_{s}-P_{I} / n\right)(n /(n-1))\left(N_{s}+N_{I}\right),{ }^{11}$

and

$\ddot{V}_{c}=\left(P_{s}-P_{I} / n\right) N_{s}$

Thus the lower bound as a fraction of the value of the firm $V$, is:

$\frac{\dot{V}_{c}}{V}>\frac{\left(P_{s}-P_{I} / n\right)(n /(n-1))\left(N_{s}+N_{I}\right)}{\left(N_{I} P_{I}+N_{s} P\right)}$

or

$\frac{\ddot{V}_{c}}{V}>\frac{\left(P_{s}-P_{I} / n_{v}\right) N_{s}}{\left(N_{I} P_{I}+N_{s} P\right)}$

\section{5.c. The Value of Control Inferred from Dual Class Shares}

In this section, we offer several scenarios, which differ in their basic assumptions:

\section{5.c.1. Prices of Superior and Inferior Shares Reflect Only Market Values of Voting Rights}

This assumption implies that market prices for both share classes are set by the non-control seekers. Thus, market prices reflect only the control premium held by non-controlseekers. This leads to two pricing equations with two unknowns:

$$
\begin{aligned}
& n E+V c_{j}=P_{I} \\
& E+V c_{j}=P_{S}
\end{aligned}
$$

where each inferior share's claim on dividends is $n$ times greater than that of each superior share, $V c_{j}$ is the unknown market control premium imbedded in share prices, and $E$ the unknown value of the dividend-only component of a superior-class share. Then, from (37 and 38) we have:

${ }^{10}$ This assumption may be unrealistic but it meant to enable to calculate the lower bound on the value of control.

${ }^{11}$ For example, if one superior share has one voting right and one fifth of $n$ inferior share has one fifth voting right, the difference in market price reflects the value of $4 / 5$ voting rights or $((n-1) / n)$.
$E=\frac{P_{s}-P_{I}}{1-n}$, and,

$V c_{j}=P_{s}-E=P_{I}-n E$

The overall value of control includes the value of control imbedded in shares held by non-control seekers, $\mathrm{j}$, which was derived above from market prices:

$\left(N_{s j}+N_{l j}\right) V c_{j}$

and the value of control possessed by the control seekers:

$\sum V c_{i}$, i.e.,

$V c=\left(N_{s j}+N_{l j}\right) V c_{j}+\sum V c_{i}$

where $N_{s j}, N_{l j}$ reflects the number of superior and inferior shares respectively held by the non-control seekers. Since we cannot directly determine the empirical value of $\sum V c_{i}$, or the overall $V c$, we will compare our model in section 4 to this only in respect to the market premium of control.

5.c.2. Inferior Shares are Exclusively Held by the Non-Control Seekers and Superior Shares are Held by the Control Seekers

In this scenario, the market price of the inferior shares reflects the non-control seeker market value of a voting right, while the price of the superior share reflects the marginal value of a voting right to the control seeker (equation 17). While a control seeker has the potential to purchase inferior shares and thereby set the market price of such control imbedded in inferior shares, the non-control seeker may find it irrational to buy superior shares, paying premiums (the marginal value) for control rights. Thus, by definition:

$P_{I}=n E+\frac{\left(V c-\sum V c_{i}\right)}{N_{I}}$

$P_{s}=E+M\left(V c_{i}\right)$,

where $M($.$) reflects the minimum marginal value of control$ for an additional increment of control held by a control seeker $i$, as shown in equation 17. Observation of $M($.$) pro-$ vides more useful information. The overall value of control held by a control seeker is the sum of all marginal values of control of all shares previously purchased. That is,

$$
\sum_{i=1}^{2} V c_{i}=\int_{0}^{N_{i}^{2}} \int_{0}^{N_{s 1}} M\left[V c_{1}\left(N_{s 1}\right), V c_{2}\left(N_{s 2}\right)\right] d N_{s 1} d N_{s 2}
$$

If we approximate the control value function of the control seekers as a linear function between each two discrete consecutive positions in $N_{s}$, then, for two control seekers, who respectively own $N_{s 1}$ and $N_{s 2}$ superior shares:

$$
\sum_{i=1}^{2} V c_{i}=\sum_{N_{1}=0}^{N_{s 1}} \sum_{N_{2}=0}^{N_{s 2}}\left\{\left(\hat{P}_{s}\left(N_{s 1}, N_{s 2}\right)-E N_{s 1} N_{s 2}\right\}\right.
$$

where $\hat{P}_{s}$ is the linearly approximated price as a function of $N$. Substituting (44) into (42), 


$$
\begin{aligned}
& P_{I}=n E+\frac{V c}{N_{I}}-\frac{\sum_{N_{1}=0}^{N_{s 1}} \sum_{N_{2}=0}^{N_{s 2}}\left\{\hat{P}_{s}\left(N_{s 1}, N_{s 2}\right)-E N_{s 1} N_{s 2}\right\}}{N_{I}} \\
& P_{s}=E\left(1-N_{s 1}-N_{s 2}\right)+\sum_{N_{1}=0}^{N_{s 1}} \sum_{N_{2}=0}^{N_{s 2}}\left\{\hat{P}_{s}\left(N_{s 1}, N_{s 2}\right)\right\}
\end{aligned}
$$

Given $W$ as the solution for a quadratic equation that is the solution of:

$$
\begin{aligned}
& \sum_{N_{1}=0}^{N_{s 1}} \sum_{N_{2}=0}^{N_{s 2}}\left\{\hat{P}_{s}\left(N_{s 1}, N_{s 2}\right)\right\}, \text { and, } V c_{i}\left(N_{i}=0\right)=0, \text { then } \\
& E=\frac{P_{s}-W}{1-N_{s 1}-N_{s 2}}, \text { and } \\
& V c=N_{I} P_{I}-\left(N_{s 1}+N_{s 2}+N_{I} n\right)\left(\frac{P_{s}-W}{1-N_{s 1}-N_{s 2}}\right)+W
\end{aligned}
$$

It is important to note that comparison between this model and that in Section 3 may be understood within the given parameters that although control seekers trade inferior shares, non-control seekers establish the control premium.

\section{5.c.3. Superior and Inferior Shares are Held by Both Con- trol- and Non-Control-Seekers}

This scenario is less restrictive than 5.c.1 and 5.c.2. It differs from 5.c. 2 only to the extent that non-control seekers trade superior shares. Here, control seeker can buy these shares from either other control seekers or from non-control seekers. In this scenario, given the market control premium reflected in superior and inferior share prices, we may estimate the control premiums held by control and non-control seekers. This scenario will require a different computational approach, which will simultaneously extract information from all firms. We observe specific holding patterns and the prices of superior and inferior shares in the market comprised of $M$ firms. Market prices are:

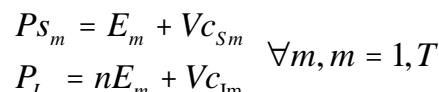

where $m$ denotes a firm, $m=1, T$. $E$ denotes the equity value as defined in equation 3 while $V c_{S m}$ and $V c_{\text {Im }}$ denote the market control premiums imbedded in superior and inferior shares.

We assume that the proportional value of control held by a control seeker, i.e., $V c_{i} / V c$, is the same for all firms with identical holding patterns (in both dimensions; equity $v s$ voting rights, and, superior $v s$ inferior). Following Papoulis [25], we will set "best estimator functions" $\hat{V} c_{S m}, \hat{V} c_{\text {Im }}$ using the notion of Minimum Mean Square Error as follows:

$$
\begin{aligned}
& \hat{V} c_{S m}=g s\left(V c_{S M}, M \neq m\right) \\
& \hat{V} c_{S I}=g I\left(V c_{I M}, M \neq m\right)
\end{aligned} \forall m, m=1, M
$$

with an error term, $e \equiv V c()-.\hat{V} c($.$) . The "best estimator$ function" is: (ii) The error term is orthogonal to any measurable function, i.e., $\operatorname{Ex}\left(e . g^{T}(V c)\right)=0$

(iii) There exists a well defined covariance matrix such

$$
\text { that, } \begin{aligned}
& \hat{\operatorname{V}} c(.)=\operatorname{Ex}(\operatorname{Vc}(.))+\operatorname{Cov}\left(\operatorname{Vc}(.)_{m}, \operatorname{Vc}(.)_{m^{\prime}}\right) \\
& \operatorname{Var}\left(\operatorname{Vc}(.)_{m^{\prime}}\right)^{-1}\left(\operatorname{Vc}(.)_{m^{\prime}}-\operatorname{Ex}\left(\operatorname{Vc}(.)_{m^{\prime}}\right)\right)
\end{aligned}
$$

where Var and Cov are variances and covariances. We solve the following set of equations:

$$
\begin{aligned}
& \hat{V} c_{s m}=P s_{m}-E_{m}=a_{1} V c_{s 1}+a_{2} V c_{s 2}+\ldots \\
& +a_{m^{\prime}} V c_{s m^{\prime}} \quad \forall m^{\prime}, m^{\prime}=1, M, m^{\prime} \neq m \\
& \hat{V} c_{\mathrm{Im}}=P I_{m}-E_{m}=b_{1} V c_{I 1}+b_{2} V c_{I 2}+\ldots \\
& +b_{m^{\prime}} V c_{\mathrm{Im}} \quad \forall m^{\prime}, m ;=1, M, m^{\prime} \neq m
\end{aligned}
$$

where $a_{i}, b_{i}$, using the notion of best estimators, are $\operatorname{Cov}(i, m) / \operatorname{Va}(i)$. Substituting the estimators $\hat{V}_{c}$ in (51) yields:

$$
\begin{aligned}
& P s_{m}-E_{m}=\hat{V} c_{S m} \\
& P_{I_{m}}-n E_{m}=\hat{V} c_{\text {Im }}
\end{aligned} \quad \forall m, m=1, T
$$

Since the Var-Cov matrix is unobservable and cannot be calculated empirically, we assume that $a_{i}, b_{i}$ are monotonic transformations, to be inferred from the data, of $\hat{a}_{i}, \hat{b}_{i}$ where the latter reflects differences in holdings of superior and inferior shares by the incumbent and rival shareholders and the public. We make the assumption that the proportional control premiums of major shareholders of two firms with similar holding pattern are highly correlated. In order to demonstrate this assumption, consider Fig. (1) which maps the three types of shareholders (major, second and the public) in terms of their positions in superior shares (the same argument applies to inferior shares).

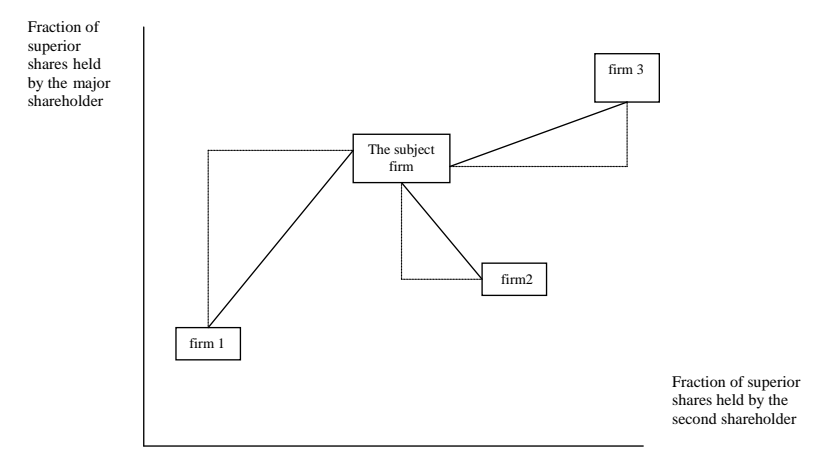

Fig. (1). Positions of the major and second major shareholder (and the public) are plotted for each of the $\mathrm{N}$ firms. The dotted lines represent the differences between the major holders for each pair of firms (vertical) and between the second major holders (horizontal). The solid lines represent the extent of dissimilarities in holding pattern for each pair of firms. The above graph represents one equation for the subject firm. There are similar equations for each of the $\mathrm{N}$ firms. 
Thus, (51) and (54), rewritten as:

$$
\begin{aligned}
& \bar{A} \vec{V} c_{s}=\vec{P}_{s}-\vec{E} \\
& \bar{B} \vec{V} c_{I}=\vec{P}_{I}-\vec{E}
\end{aligned}
$$

where

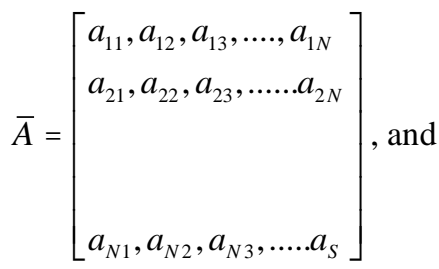

$\bar{B}=\left[\begin{array}{c}b_{11}, b_{12}, b_{13}, \ldots ., b_{1 N} \\ b_{21}, b_{22}, b_{23}, \ldots . . b_{2 N} \\ \\ b_{N 1}, b_{N 2}, b_{N 3}, \ldots . . b_{S}\end{array}\right] \cdot 1 / n$

Note that $\bar{B}$ is multiplied by $1 / n$, the multiple of dividend claims of inferior relative to superior shares. The solution for the vector $E$ in (55) is independent of the solution for $E$ in equation (56). Thus, our final solution with vector $E$ is identical in both equations, while using the following linear estimator:

$$
\left[\begin{array}{c}
\bar{A} \vec{V} c_{s} \\
\bar{B} \vec{V} c_{I}
\end{array}\right] \bar{T}=\left[\begin{array}{c}
\vec{P}_{s}-\vec{E} \\
\vec{P}_{I}-\vec{E}
\end{array}\right]
$$

where the solution is:

$\bar{T}=\bar{A}^{-1}\left(\vec{P}_{s}-\vec{E}\right)=B^{-1}\left(\vec{P}_{I}-\vec{E}\right)$

and the common vector $E$ is:

$$
\vec{E}=\left(\bar{A}^{-1}-\bar{B}^{-1}\right)^{-1} \cdot\left(\bar{A}^{-1} \vec{P}_{s}-\bar{B}^{-1} \vec{P}_{I}\right)
$$

\section{COMPUTATIONAL ILLUSTRATIONS}

In this section, we provide computational illustrations of the models presented in Sections 3 to 5. After introducing our data set in 6.a, we compute the lower bounds for control value of our firms as in Section 5. In Section 6.c, we perform computations for the multiple control rival model presented in Section 3 and the dual class ownership model in Sections 4 and 5. We illustrate these models in Section 6.d to determine the best fit. Finally, we estimate an empirical demand function for control in Section 6.e

\section{6.a. Data}

Our data is drawn from a sample of 40 Israeli firms that underwent share equalization procedures (dual to single class recapitalization) during the period 1986-1999. The firms represented a fairly broad array of industries, including real estate, chemical and metal investment companies. Each of the firms had two classes of shares and between one and four major shareholders with known shareholding levels. In all but 2 cases, superior shares had a one-fifth claim on dividends relative to inferior shares. Table $\mathbf{3}$ presents additional summary statistics of the firms in the sample.

\section{6.b Computing the Lower Bound of the Overall Value of Control}

Following the model presented in Section 5.c, we calculate the minimum overall value of control as a fraction of the total equity value. This is accomplished by assuming that market prices of shares owned by non-control seekers contain no control premium. In this case, the difference between the superior and inferior shares can easily imply the overall value of control. On average, lower bounds for control in our sample were $13.43 \%$ of overall equity value, ranging from $.09 \%$ to $32.27 \%$. The standard deviation for lower bounds across firms was $10.6 \%$.

\section{6.c. Estimating Control Value Based on Models 5c.1, 5.c.2 and 5.c.3}

Table 4 lists numerical results for our example based on seven selected firms in our sample of 40 firms. Unlike in Section 6.a where we assume that market shares contain no control premium, here we estimate control values based on assumptions given in each section 5.c.1, 5.c.2 and 5.c.3. Computational results are given in Table $\mathbf{4}$ for the three assumption sets.

\section{6.d. Discussion of the Numerical Results of the Models}

Here, based on OLS procedures, we compare control values imbedded in market prices based on models given in 5.c.1, 5.c. 2 and 5.c.3 to the predicted model prices given in Section 3. In other words, we wish to see which version of our estimation approaches fits best with the empirical data.

\begin{tabular}{|c|c|c|c|}
\hline $\begin{array}{c}\text { Average number of days between announcement and share } \\
\text { equalization }\end{array}$ & 86 & $\begin{array}{c}\text { Average proportional equity holding of the largest share- } \\
\text { holder }\end{array}$ & $44.97 \%$ \\
\hline $\begin{array}{l}\text { Average premium of superior over inferior shares before the } \\
\text { announcement }\end{array}$ & $41.03 \%$ & $\begin{array}{l}\text { Average voting rights proportion held of the largest } \\
\text { shareholder }\end{array}$ & $52.32 \%$ \\
\hline $\begin{array}{l}\text { Average court award to control owners as a proportion of supe- } \\
\text { rior class equity value }\end{array}$ & $15.42 \%$ & $\begin{array}{c}\text { Average proportional holding of the inferior shares by the } \\
\text { major shareholder in the firm }\end{array}$ & $33.26 \%$ \\
\hline Average size of assets of the firms in the sample & $\begin{array}{l}138.8 \mathrm{mmN} \\
\text { IS }\end{array}$ & $\begin{array}{c}\text { Average proportional holding of the superior shares by the } \\
\text { major shareholder in the firm }\end{array}$ & $57.68 \%$ \\
\hline Equity to total assets of the firms in the sample & $14.92 \%$ & & \\
\hline
\end{tabular}
Results from our illustration are given in Table $\mathbf{5}$ and suggest that the model given in Section 5.c.3 best fits the data.

Table 3. Sample Summary Statistics 
Table 4. $\quad P_{s}$ and $P_{I}$ Denote the Market Prices for the Superior and Inferior Shares Respectively

\begin{tabular}{|c|c|c|c|c|c|c|c|c|}
\hline \multirow[b]{2}{*}{ Name } & \multirow[b]{2}{*}{$\boldsymbol{P}_{s}$} & \multirow[b]{2}{*}{$\boldsymbol{P}_{I}$} & \multicolumn{2}{|c|}{ 5.c.1 } & \multicolumn{2}{|c|}{ 5.c. 2} & \multicolumn{2}{|c|}{ 5.c. 3} \\
\hline & & & $\begin{array}{c}\text { Implied } \\
\text { Equity } \\
\text { Value }\end{array}$ & $\begin{array}{l}\text { Control } \\
\text { Premium - } \\
\text { Public }\end{array}$ & $\begin{array}{c}\text { Implied } \\
\text { Equity } \\
\text { Value }\end{array}$ & $\begin{array}{l}\text { Control } \\
\text { Premium - } \\
\text { Public }\end{array}$ & $\begin{array}{l}\text { Implied } \\
\text { Equity } \\
\text { Value }\end{array}$ & $\begin{array}{c}\text { Control } \\
\text { Premium - } \\
\text { Public }\end{array}$ \\
\hline King & 3.00 & 9.45 & 1.612 & 0.2745 & 1.739 & 0.0794 & 1.398 & 0.3168 \\
\hline Baruch & 7.50 & 22.50 & 3.750 & 0.1802 & 6.384 & 0.1487 & 3.879 & 0.1740 \\
\hline Pama & 22.06 & 92.15 & 17.525 & 0.1045 & 19.248 & 0.3735 & 8.846 & 0.3043 \\
\hline Klal & 1.10 & 4.99 & 0.972 & 0.0307 & 1.044 & 0.3719 & 0.431 & 0.1612 \\
\hline Defron & 55.00 & 200.00 & 36.250 & 0.2299 & 23.745 & 0.6438 & 22.400 & 0.3997 \\
\hline Polak & 24.00 & 67.50 & 10.875 & 0.1640 & 21.122 & 0.1105 & 12.96 & 0.1379 \\
\hline All firms & & & & 0.1261 & & 0.2808 & & 0.1971 \\
\hline
\end{tabular}

The implied equity-only value of a single share imbedded in both shares is given in the first column for each alternative. The control premium imbedded in the market price of shares owned by non-control seekers is given in the second column of each alternative.

Table 5. Results of the OLS Procedure Concerning Control Premiums Based on Functions Defined by Each of the Three Models Given in 5.c.1, 5.c.2 and 5.c.3

\begin{tabular}{|c|c|c|c|}
\hline \multicolumn{4}{|c|}{$\begin{array}{l}\text { Control Premium } \\
\text { in Market Price = Constant }+ \text { Coefficient }\{\text { Model Value }\} \\
\text { as in Model: }\end{array}$} \\
\hline \multirow[t]{6}{*}{ 5.c. 1} & 0.0001 & 0.4421 & \\
\hline & & (2.9112) & \\
\hline & & $\mathrm{F}$ & 23.206 \\
\hline & & $\mathrm{R}$ & 0.654 \\
\hline & & Adjusted R & 0.428 \\
\hline & & Standard Error & 1.246 \\
\hline \multirow[t]{6}{*}{ 5.c. 2} & 0.1973 & 0.3137 & \\
\hline & & (1.8786) & \\
\hline & & $\mathrm{F}$ & 4.214 \\
\hline & & $\mathrm{R}$ & 0.12 \\
\hline & & Adjusted R & 0.346 \\
\hline & & Standard Error & 0.650 \\
\hline \multirow[t]{6}{*}{ 5.c. 3} & 0.1201 & 0.4127 & \\
\hline & & (3.62889) & \\
\hline & & $\mathrm{F}$ & 31.155 \\
\hline & & $\mathrm{R}$ & 0.7846 \\
\hline & & Adjusted R & 0.6156 \\
\hline & & Standard Error & 2.234 \\
\hline
\end{tabular}

\section{6.e. Estimated Demand Curve for Control}

Using models in 5.c.1 and 5.c.3, we estimate the demand curve for control for the firms in our sample. Based on the assumption of a declining linear demand curve, we compute a slope coefficient $a=\frac{\bar{V} c}{N}$. Slope coefficients for the models presented in Sections 5.c.1 and 5.c.2 were -1.42152 and -
1.9580 , respectively. These results suggest that the demanded level of control declines as ownership of voting rights increases in a manner consistent with Jensen and Meckling [11].

\section{CONCLUSIONS}

The primary purpose of this paper has been to introduce and explore analytical valuation models for private benefits enjoyed by corporate control seekers. Lack of explicit observable data, for some firms, even intentional omission of data relevant to control benefits renders the direct valuation of private benefits of control almost impossible. We structured an equilibrium model to express vote values as functions of power indices and value of control. Power indices can be inferred from the distribution of shares among shareholders while vote values can be inferred from market prices of shares. Hence, the value of corporate control is implied from these distributions and market values. After structuring a control demand function, we introduced and evaluated methodologies for "backing out" corporate control value.

We discussed the impact of multiple share classes on inferring control value from share distributions and vote values, focusing first on control value as a simple function of relative values of dual class shares. However, these computations are not helpful for single class firms nor do they capture possible complications resulting from the distributions of shares. To accommodate these issues, we established a lower bound of control. We then discussed the distributions of different classes of shares among shareholders and how these distributions might impact valuation functions. If we are willing to assume that distributions of shares and votes among controlling and non controlling shareholders reflect the value of private benefits generated by the firm, firms with similar patterns of ownership distribution should exhibit similar patterns of private benefits production. Hence, we introduced a regression analysis procedure applied to distributions of classes of shares among shareholders to capture this relationship. We presented numerical illustrations suggesting that this regression procedure seems to be effective in evaluating control as a function of the distribution of shares and relative values of share classes. 


\section{APPENDICES}

\section{A.1. Computational Technique for Equation 21}

In this appendix, we demonstrate a numerical solution procedure for Equation (21). Applying a Taylor Series expansion to equation (21) yields:

$$
\begin{aligned}
& {\left[f\left\{P I_{N 1 / N 2}\right\}+f\left\{P I_{N 2 / N 1}\right\}\right]+} \\
& {\left[\frac{d}{d N_{2}} f\left\{P I_{N 2 / N 1}\right\} \Delta N_{2}+\frac{d}{d N_{1}} f\left\{P I_{N 1 / N 2}\right\} \Delta N_{2}\right] \rho+0.5 *\left[\frac{d^{2}}{d N_{1}{ }^{2}} f\left\{P I_{N 2 / N 1}\right\}\left(\Delta N_{2}\right)^{2}+\frac{d^{2}}{d N_{1}{ }^{2}} f\left\{P I_{N 1 / N 2}\right\}\left(\Delta N_{2}\right)^{2}\right] \rho=1}
\end{aligned}
$$

assuming that (21) is twice differentiable. In this appendix, we demonstrate how to obtain the value of a vote by using the Finite Difference forward method, where $i, j$ denotes the grid points over $N_{1}, N_{2}, i=1, N c-N_{l}, J=1, N c-N_{2}$ and $h$ is the increment on both axis. We define the following:

$$
\begin{aligned}
& f\left\{P I_{N 1 / N 2}\right\}=U(i, j) . \\
& \frac{d}{d N_{1}} f\left(P I_{N 2, N 1}\right)=u(i, j) \frac{P I(i, j+1)-P I(i, j)}{h}+P I(i, j) \frac{u(i, j+1)-u(i, j)}{h} \\
& \frac{d}{d N_{2}} f\left(P I_{N 2, N 1}\right)=u(i, j) \frac{P I(i+1, j)-P I(i, j)}{h}+P I(i, j) \frac{u(i+1, j)-u(i, j)}{h}
\end{aligned}
$$

Thus, Equation (21) is expanded as follows:

$$
\begin{aligned}
& U(i, j)+U(j, i)+\rho \frac{\Delta i}{h} P I(i, j)[u(i+1, j)-u(i, j)]+\rho u(i, j) \frac{\Delta i}{h}[P I(i+1, j)-P I(i, j)]+ \\
& \rho \frac{\Delta i}{h} P I(i, j)[u(i, j+1)-u(i, j)]+\rho u(i, j) \frac{\Delta i}{h}[P I(i, j+1)-P I(i, j)]=1
\end{aligned}
$$

Starting backward from the grid point $U\left(N_{c}-1, N_{c}-1\right)$ and we solve the equation which contains two unknowns and two variables which are given by the boundary conditions:

$$
\begin{aligned}
& U\left(N_{c}, j\right)=1 \\
& U\left(i, N_{c}\right)=1
\end{aligned}
$$

The diagonal matrix of equations (only under the diagonal $i=j$ ) may be completely solved under the following definitions:

- $\quad f\{\}$ is symmetric i.e. $f_{1}\left\{N_{1} / N_{2}\right\}=f_{2}\left\{N_{1} / N_{2}\right\}$ or $u(i, j)=u(j, i)$

- $\quad P I$ is given by the Shapley Oceanic Index or the Owen Power Index as applied by Teall [1996].

- $\quad i$ and $j$ are set at 100 shares interval and $D i$ and $D j$ are one share each

Under the above assumptions and (25) we simultaneously solve two equations for each grid point, $i, j, i \neq j$ :

$$
\begin{aligned}
& u(j, i)+u(i, j)(1-\rho[4 P I(i, j)-P I(i+1, j)-P I(i, j+1)])+P I(i, j) \rho(u(i+1, j)+u(i, j+1))=1 \\
& u(i, j)+u(j, i)(1-\rho[4 P I(j, i)-P I(j+1, i)-P I(j, i+1)])+P I(j, i) \rho(u(j+1, i)+u(j, i+1))=1
\end{aligned}
$$

Our computational procedure is demonstrated with an example with two contestants for control (Players 1 and 2) who own between 0 and $50 \%$ of shares. The remaining shares are owned by minor shareholders.

Table A1. The Fractional Value of Control Owned by Player 1 (Vertical Column) when his Opponent (Player 2) Owned the Fraction of Shares Shown in the First Row. $(\rho=.05)$. The Shapley Power Index was Used for 1000 Shares

\begin{tabular}{|c|c|c|c|c|c|c|}
\hline $\mathbf{0 . 5}$ & $\mathbf{0 . 4}$ & $\mathbf{0 . 3}$ & $\mathbf{0 . 2}$ & $\mathbf{0 . 1}$ & $\mathbf{0}$ & $\begin{array}{c}\text { Fraction of Shares } \\
\text { Player 1/Player 2 }\end{array}$ \\
\hline 0 & 0 & 0 & 0 & 0 & 0 & 0 \\
\hline \hline 0 & 0.081295 & 0.176984 & 0.253769 & 0.326309 & 0.504892 & 0.1 \\
\hline 0 & 0.119776 & 0.292941 & 0.412312 & 0.551731 & 0.709454 & 0.2 \\
\hline 0 & 0.192198 & 0.375604 & 0.553283 & 0.682162 & 0.814601 & 0.3 \\
\hline 0 & 0.326222 & 0.535174 & 0.661218 & 0.77096 & 0.877932 & 0.4 \\
\hline & 1 & 1 & 1 & 1 & 1 & 0.5 \\
\hline
\end{tabular}




\section{A.2. Numerical Procedure: Computing the Demand Function (Section 4)}

As in Appendix A.1, we start to solve Equations (30) and (31) by expanding as follows:

$$
\begin{aligned}
& f\left(P I_{N 1, N 2}\right)\left\{\left(\bar{V} c-a N_{1}\right)(1-\rho)+\rho\left(\bar{V} c-a N_{1}-a \Delta N_{2}\right)\right\}+\left(\bar{V} c-a N_{2}\right) f\left(P I_{N 2, N 1}\right)+ \\
& \rho\left(\bar{V} c-a N_{1}-a \Delta N_{2}\right)\left(\frac{d}{d N_{1}} f\left(P I_{N 1, N 2}\right) \Delta N_{2}+\frac{d}{d N_{2}} f\left(P I_{N 1, N 2}\right) \Delta N_{2}\right)=\bar{V} c-a N_{2} \\
& f\left(P I_{N 2, N 1}\right)\left\{\left(\bar{V} c-a N_{2}\right)(1-\rho)+\rho\left(\bar{V} c-a N_{2}-a \Delta N_{2}\right)\right\}+\left(\bar{V} c-a N_{1}\right) f\left(P I_{N 1, N 2}\right)+ \\
& \rho\left(\bar{V}_{c}-a N_{2}-a \Delta N_{2}\right)\left(\frac{d}{d N_{1}} f\left(P I_{N 2, N 1}\right) \Delta N_{2}+\frac{d}{d N_{2}} f\left(P I_{N 2, N 1}\right) \Delta N_{2}\right)=\bar{V} c-a N_{1}
\end{aligned}
$$

We then insert the following demand function for control as a parameter: $a=\frac{\bar{V} c}{N}$

$$
u(i, j)=\frac{\bar{V} c-a j-b(i, j) \rho(\bar{V} c-a i+a h)}{(1-\rho)(\bar{V} c-a i)+\rho(\bar{V} c-a i-a h)+\bar{V} c-a i+A(i, j)}
$$

For the diagonal elements of the matrix, i.e. $N_{1}=N_{2}$ where

$$
\begin{aligned}
& A(i, j)=-4 P I(i, j)+P I(i+1, j)+P I(i, j+1) \\
& b(i, j)=P I(i, j)(u(i+1, j)+u(i, j+1))
\end{aligned}
$$

Condition (A6) becomes the minimum of the following two equations at each grid point:

$\left(\bar{V} c-a N_{1}\right)\{u(i, j)(P I(i+1, j)+P I(i, j+1)-4 P I(i, j))+P I(i, j)(u(i, j+1)+u(i+1, j))\}$

$O R$

$\left(\bar{V}_{c}-a N_{2}\right)\{u(j, i)(P I(j+1, i)+P I(j, i+1)-4 P I(j, i))+P I(j, i)(u(j, i+1)+u(j+1, i))\}$

If the first equation, for example, is the minimum then we need to solve two equations with two unknowns:

$u(i, j) c(i, j)+u(j, i) d(i, j)+f(i, j) A(i, j)=d(i, j)$

$u(j, i) d(j, i)+u(i, j) c(j, i)+f(j, i) A(j, i)=d(j, i)$

where:

$$
\begin{aligned}
& c(i, j)=(1-\rho)(\bar{V} c-a i)+\rho(\bar{V} c-a i-a h) \\
& c(j, i)=(1-\rho)(\bar{V} c-a j)+\rho(\bar{V} c-a j-a h) \\
& d(i, j)=\bar{V} c-a j \\
& d(j, i)=\bar{V} c-a i \\
& f(i, j)=\rho(\bar{V} c-a i-a h) \\
& f(j, i)=\rho(\bar{V} c-a j-a h) \\
& A(i, j)=-4 P I(i, j)+P I(i+1, j)+P I(i, j+1) \\
& A(j, i)=-4 P I(j, i)+P I(j+1, i)+P I(j, i+1)
\end{aligned}
$$

The solution for (A7) is:

$$
u(i, j)=\frac{d(i, j)-f(i, j) A(i, j)-\frac{d(i, j)}{d(j, i)}(d(j, i)-f(j, i) A(j, i))}{c(i, j)-c(j, i)}
$$


Simulation results are as follows:

Table A2. Fractional Value of Control Owned by Player 1 (Vertical Column) when his Opponent (Payer 2) Owned the Fraction of Shares Shown in the First Row $(\rho=.05)$. The Shapley Power Index was Used for 1000 Shares

\begin{tabular}{|c|c|c|c|c|c|c|}
\hline $\begin{array}{c}\text { Fraction of Shares } \\
\text { Player 1/Player 2 }\end{array}$ & $\mathbf{0}$ & $\mathbf{0 . 1}$ & $\mathbf{0 . 2}$ & $\mathbf{0 . 3}$ & $\mathbf{0 . 4}$ & $\mathbf{0 . 5}$ \\
\hline \hline 0 & 0 & 0 & 0 & 0 & 0 & 1 \\
\hline 0.1 & 0.511929 & 0.327664 & 0.252197 & 0.174068 & 0.087762 & 1 \\
\hline 0.2 & 0.72862 & 0.561003 & 0.415065 & 0.314703 & 0.129034 & 1 \\
\hline 0.3 & 0.847881 & 0.702912 & 0.56405 & 0.378701 & 0.191398 & 1 \\
\hline 0.4 & 0.926844 & 0.836739 & 0.723334 & 0.587402 & 0.357472 & 1 \\
\hline 0.5 & 0 & 0 & 0 & 0 & 0 & 0 \\
\hline
\end{tabular}

\section{A.3. Computational Procedures for the Shapley Power Index}

Milnor and Shapley [1978] introduced the following estimate of power possessed by a control seeker:

$$
\Omega_{Y}=\sum_{S \in M-\{Y\}} \int_{\left\langle\frac{0.5-W(S \cup Y}{\Phi}\right\rangle}^{\left\langle\frac{0.5-W(S)}{\Phi}\right\rangle} t^{S} \cdot(1-t)^{m-S-1} d t
$$

where

$M$-A set of major players who are defined as control seekers.

$m$ - The number of major players

$\{Y\}$ - The player for whom the index is computed.

$W(S)$ - Fraction of the voting rights held by player $\mathrm{S}$.

$\Phi$ - Fraction of voting rights held by the players who do not wish to have control.

$t$ - The integration parameter which follows: $\left\{\begin{array}{l}t=0 \quad \text { if } \quad t \leq 0 \\ t \quad \text { if } 1>t>0 \\ t=1 \text { if } t \geq 1\end{array}\right.$

computed as $t=\operatorname{MAX}\left[0, \operatorname{MIN}\left[\frac{0.5-W(S)}{\Phi}, 0\right\}\right]$

\section{REFERENCES}

[1] Jensen M, Meckling W. Theory of the firm, managerial behavior, agency costs and ownership structure. J Financ Econ 1976; 3: 30560.

[2] Lease RC, McConnell JJ, Mikkelson WH. The market value of differential voting rights in closely held corporations. J Bus 1984; 57: 443-67.

[3] Lease RC, McConnell JJ, Mikkelson WH. The market value of control in publicly-traded corporations. J Financ Econ 1985; 11: 439-71.

[4] Levy H. Economic evaluation of voting power of common stock. J Finance 1983; 38: 79-93.

[5] Alchian AA, Demsetz H. Production, information costs, and economic organization. Am Econ Rev 1972; 62: 777-95.

[6] Fama E. Agency problems and the theory of the firm. J Polit Econ 1980; 88: 288-307.

[7] Gordon M. The investment, financing and valuation of the corporation, Homewood Illinois: Richard D. Irwin 1962.

[8] Nenova T. The value of corporate voting rights and control: a cross-country analysis. J Financ Econ 2003; 68: 325-52.
[9] Dyck A, Zingales L. Private benefits of control: an international comparison. J Finance 2004; 59: 537-600.

[10] DeAngelo H, DeAngelo L. Managerial ownership of voting rights. J Financ Econ 1985; 14: 35-9.

[11] Shapley LS, Shubik M. A method for evaluating the distribution of power in a committee system. Am Polit Sci Rev 1954; 48: 787-92.

[12] Milnor JW, Shapley LS. Values of large games II: oceanic games. Math Oper Res 1978; 3: 290-307.

[13] Owen G. Multilinear extensions of games. Manage Sci 1972; 18 : 64-79.

[14] Rydqvist K. Empirical investigation of the voting premium. Unpublished Working Paper, Northwestern University 1987.

[15] Bergstrom C, Rydqvist K. Ownership of equity in dual class firms. J Bank Finance 1990; 14: 237-53.

[16] Robinson C, Alan W. The value of a vote in the market for corporate control. Unpublished Working Paper, York University 1989.

[17] Zingales L. What determines the value of corporate voting rights? Q J Econ 1995; 110: 1047-73.

[18] Teall JL. A binomial model for the valuation of corporate voting rights. J Bus Financ Account 1996; 23(4): 603-16. 
[19] Zingales L. The value of the voting right: a study of the milan stock exchange experience. Rev Financ Stud 1994; 7: 125-48.

[20] Zwiebel J. Block investment and partial benefits of corporate control. Rev Econ Stud 1995; 62: 161-85.

[21] Hauser S, Lauterbach B. The value of voting rights to majority shareholders: evidence from dual class stock unifications. Unpublished Working Paper, Bar Ilan University 2000.

[22] Christoffersen S, Musto CGD, Reed A. Vote trading and information aggregation. Unpublished working paper, University of Pennsylvania 2006
[23] Burkhart M, Gromb D, Panunzi F. Agency conflicts in public and negotiated transfers of corporate control. J Finance 2000; 50: 64778 .

[24] Forsythe G, Wasow W. Finite difference method for partial differential equations. Weily New York 1960.

[25] Papoulis A. Probability, random variables \& stochastic processes. $3^{\text {rd }}$ ed. McGraw-Hill 1991.

(C) Kraizberg and Teall; Licensee Bentham Open.

This is an open access article licensed under the terms of the Creative Commons Attribution Non-Commercial License (http://creativecommons.org/licenses/by$\mathrm{nc} / 3.0 /$ ) which permits unrestricted, non-commercial use, distribution and reproduction in any medium, provided the work is properly cited. 